\title{
Design of a sustainable personal mobility system (SPMS)
}

\author{
Ralph O. Buchal, Adam Day, J. Cooper Robinson \\ Faculty of Engineering \\ The University of Western Ontario \\ London, Ontario, Canada \\ rbuchal@eng.uwo.ca
}

\begin{abstract}
Engineers must consider social and environmental impacts of engineering, particularly sustainability. Student design projects should help develop this competency. A suitable theme is design to address the challenge of global warming. Personal transportation is a major contributor to greenhouse gas (GHG) emissions, and students at Western have worked for several years on the design of a Sustainable Personal Mobility System (SPMS). SPMS is a vehicle sharing system using ultralight electric vehicles (ULVs) powered by renewable energy. Western undergraduate students have developed and analysed the SPMS concept, and have concluded that it is feasible to provide convenient and cost-effective personal mobility while reducing GHG by at least $85 \%$ compared to private cars. The design of a suitable ULV would be an excellent new direction for student projects, including existing solar car teams.
\end{abstract}

\section{Introduction}

The new CEAB accreditation guidelines require that all engineering graduates possess the "ability to analyse social and environmental aspects of engineering activities. Such abilities include an understanding of the interactions that engineering has with the economic, social, health, safety, legal, and cultural aspects of society; the uncertainties in the prediction of such interactions; and the concepts of sustainable design and development and environmental stewardship [1]." Engineering educators must infuse issues of sustainability throughout the curriculum, and make these issues central to design education.
The environmental challenges facing civilization have been well documented [2][3]. Perhaps the most pressing is the challenge of global warming. Scientific consensus is that the increase in global average temperature must be limited to no more than about 2 degrees Celsius to avoid the worst consequences of climate change. This will require GHG reductions of $80-90 \%$ over the next $10-20$ years [3][4]. It is the responsibility of engineers to propose solutions that are technically and economically feasible, and socially acceptable. This is a theme for student design projects that really matter.

\section{Designing a Sustainable Personal Mobility System (SPMS)}

One of the largest contributors to GHG emissions is personal transportation. Business-as-usual thinking will not provide the reductions needed to avoid the worst consequences of climate change. We need to completely rethink the problem of personal mobility, and the role and nature of cars. For the past several years, students and faculty at the University of Western Ontario have been working on designing a Sustainable Personal Mobility System (SPMS). The concept was originally articulated by Buchal [5]. Since then, we have learned of a very similar and much more comprehensive plan proposed by Mitchell et al. as part of the MIT Smart Cities project [6]. They propose four fundamental ideas that form the basis for a sustainable personal mobility system:

1. Intelligent, interconnected electric vehicles

2. A "mobility internet" to coordinate and manage traffic, pricing and other services 
3. Integration of electric vehicles with a smart power grid that uses distributed renewable energy sources

4. Dynamic pricing models to manage supply and demand of vehicles, parking spaces, road space, energy use, etc.

Our SPMS builds on these ideas. Fundamentally, SPMS is based on a vehicle sharing model. Users select vehicles based on need, and pay per use. A key component of SPMS is a fleet of ultralight, short range electric vehicles (ULVs).

\section{$3 \quad$ SPMS feasibility analysis}

Several Western Engineering student design teams have developed and analysed the SPMS concept to answer several questions:

1. Can SPMS satisfy personal mobility needs at least as well as private cars?

2. What are the technical requirements and specifications for the ULVs used in SPMS?

3. Can SPMS reduce GHG emissions by the substantial amounts needed to address climate change?

4. Can SPMS reduce the cost of personal mobility compared to private cars?

The overall feasibility of SPMS depends on satisfactory answers to these questions.

\section{Show me the numbers!}

A credible plan for sustainable mobility must be based on numbers, not unsupported assertions, assumptions and guesses. Estimating numbers requires students to grapple with several questions including:

- What are the key parameters and variables? How are they related?

- What numbers do we know? How certain are they?

- What assumptions are being used? What is the justification?

- How can we quantify the degree of uncertainty in estimates?

\subsection{Can SPMS satisfy personal mobility needs?}

The basic requirement of a personal mobility system is to transport people and their personal cargo conveniently, quickly, comfortably, safely and inexpensively.

For the majority of urban trips, traveling by private car involves traffic congestion, cost and hassle of parking, and poor vehicle utilization for single occupant short trips. SPMS is an integrated transportation service that can optimize vehicle flow and parking to minimize end-to-end travel time. Even without integration, a vehicle sharing system can match private cars for many trips.

\subsection{What are the vehicle requirements and specifications?}

SPMS will offer users a selection of vehicles to choose from depending on the requirements of each trip. Most urban driving involves single occupant vehicles travelling distances of less than about $50 \mathrm{~km}$ at speeds of less than $100 \mathrm{~km} / \mathrm{h}$. A vehicle needs to be designed specifically for this type of trip.

In terms of well-to-wheel efficiency and GHG emissions, battery electric vehicles have been shown to be more efficient than other available alternatives [7]. Furthermore, electric vehicles can reduce GHG emissions to zero if electric power is from renewable sources. In the future, it is likely that energy will be more expensive and scarce than it is now. We must reduce demand by reducing the amount of energy required for personal transportation, measured in $\mathrm{kW}$ h/person-km.

Energy consumption can be reduced by decreasing vehicle weight and constraining performance requirements. Vehicles should be just big enough, and with just enough performance, to satisfy the transportation requirements.

If we assume the vehicle will have one (or two) seats, with a range of $50 \mathrm{~km}$ and a top speed of $100 \mathrm{~km} / \mathrm{h}$, we can then estimate the engine power, battery capacity and overall vehicle weight. Rough estimates can be compared with similar vehicles, and refined through more detailed analysis and experimentation.

A suitable benchmark is the TREV (two-seater renewable energy vehicle), built by students at the University of South Australia [8]. TREV is a 2-seat vehicle with a range of $150 \mathrm{~km}$ and a top speed of 120 $\mathrm{km} / \mathrm{h}$. It has a mass of $300 \mathrm{~kg}$, uses a $25 \mathrm{~kW}$ motor, and has a $5.5 \mathrm{~kW}$-h battery pack. The energy consumption based on actual testing is $62 \mathrm{~W}-\mathrm{h} / \mathrm{km}$.

Mitchell et al. [6] estimate that their ULV will weigh less than $450 \mathrm{~kg}$, with a $4 \mathrm{~kW}$-h battery, and two $5 \mathrm{~kW}$ motors. However, they do not provide justification for these estimates. The MIT ULV is heavier, and has a smaller motor and battery pack, so it will likely have a lower top speed and shorter range than the TREV. 


\subsection{Modeling vehicle performance}

The performance of an electrical vehicle can be modeled and simulated to determine estimates for energy consumption, battery capacity, power requirements and range. Excellent references are available, e.g. [9], so it is not necessary to develop the model from scratch.

The tractive effort from the vehicle motor must equal the forces resisting motion of the vehicle, including: rolling resistance, aerodynamic drag, hill climbing, and inertial force when accelerating. This is shown in Eqs. (1) to (5). The key vehicle parameters affecting the resistance forces and hence power required include: vehicle mass, gradient of hill, vehicle acceleration, speed, coefficient of rolling resistance, frontal area and coefficient of drag.

$$
\begin{gathered}
F_{t e}=F_{r r}+F_{a d}+F_{h c}+F_{a} \\
F_{r r}=\mu_{r r} m g \\
F_{a d}=\left(\frac{1}{2}\right) \rho A C_{d} v^{2} \\
F_{h c}=m g \sin \theta \\
F_{a}=m a
\end{gathered}
$$

Where

$$
\begin{aligned}
F_{t e} & =\text { Total tractive force, } N \\
F_{r r} & =\text { Rolling resistance, } N \\
F_{a d} & =\text { Aerodynamic drag, } N \\
F_{h c} & =\text { Hill climbing force, } N \\
F_{a} & =\text { Inertial force of acceleration, } N \\
\mu_{r r} & =\text { Coefficient of rolling resistance } \\
m & =\text { Vehicle mass } \\
g & =\text { Acceleration of gravity } \\
\rho & =\text { Air density, } \mathrm{kg} / \mathrm{m}^{3}
\end{aligned}
$$

$$
\begin{aligned}
A & =\text { Frontal area of vehicle, } \mathrm{m}^{2} \\
C_{d} & =\text { Coefficient of drag } \\
v & =\text { Vehicle speed, } \mathrm{m} / \mathrm{s} \\
\theta & =\text { Grade of hill being climbed, rad } \\
a & =\text { Vehicle acceleration, } \mathrm{m} / \mathrm{s}^{2}
\end{aligned}
$$

The power required is the product of tractive force and speed,

$$
P_{t e}=F_{t e} v
$$

The corresponding battery power is

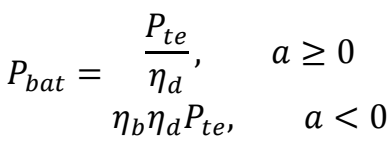

where

$$
\begin{aligned}
& \eta_{d}=\begin{array}{l}
\text { Drivetrain efficiency, battery output to } \\
\text { wheels }
\end{array} \\
& \eta_{b}=\text { Battery charge/discharge efficiency }
\end{aligned}
$$

Eq. (7) models regenerative braking by representing power flow into the battery during deceleration. The amount of energy that can be recovered during deceleration depends on the drivetrain and battery charging efficiencies.

In order to model the vehicle performance, values for key parameters must be estimated, with justification, as shown in Table 1. 
Table 1. Estimated model parameter values.

\begin{tabular}{|c|c|}
\hline Parameter & Estimated values \\
\hline$\mu_{r r}$ & $\begin{array}{l}\mu_{r r} \text { ranges from } 0.007 \text { to } 0.014 \text { for new } \\
\text { passenger car tires [10], and is as low as } \\
0.0055 \text { for solar car tires [11]. } \\
\text { For our model, we will assume a value } \\
\text { of } 0.007\end{array}$ \\
\hline$m$ & $\begin{array}{l}\text { We will use a value of } 300 \mathrm{~kg} \text {. This is } \\
\text { comparable to solar cars, and to TREV } \\
\text { [8]. }\end{array}$ \\
\hline$A$ & $\begin{array}{l}\text { We assume a value of } 1.5 \mathrm{~m}^{2} . \text { This is is } \\
\text { comparable to the value for the Loremo } \\
\text { vehicle [12]. }\end{array}$ \\
\hline$C_{d}$ & $\begin{array}{l}\text { Passenger cars have values around } 0.3 \text {. } \\
\text { The Loremo claims a value of } 0.2 \text { [12], } \\
\text { and well designed solar cars can be as } \\
\text { low as } 0.1 \text { [11]. We will assume a value } \\
\text { of } 0.2 \text {. }\end{array}$ \\
\hline$\eta_{d}$ & $\begin{array}{l}\text { For hub motors, this is approximately } \\
\text { equal to the motor efficiency. The } \\
\text { efficiency varies with operating point, } \\
\text { but is typically over } 85 \% \text { for most } \\
\text { motors under most conditions. We will } \\
\text { assume } 85 \% \text {. }\end{array}$ \\
\hline$\eta_{b}$ & $\begin{array}{l}\text { Lithium-ion batteries have a } \\
\text { charge/discharge efficiency of } 80-90 \% \\
\text { [13]. We will assume a value of } 85 \% \text {. }\end{array}$ \\
\hline
\end{tabular}

The model with these parameter values can be used to estimate peak motor requirements, energy consumption, acceleration, top speed and range for a variety of scenarios. The vehicle range is a function of the total energy capacity of the batteries, and the actual power used to move the vehicle. The range is easy to calculate for a vehicle traveling at a constant speed - it is a simple function of battery energy capacity, overall drivetrain efficiency, tractive power, and speed. Several steady-state scenarios were modeled, as shown in Table 2.
Table 2. Steady state scenarios.

\begin{tabular}{|l|l|l|}
\hline Scenario & Power & $\begin{array}{l}\text { Energy } \\
\text { consumption }\end{array}$ \\
\hline $\begin{array}{l}\text { Constant speed of } \\
100 \mathrm{~km} / \mathrm{h}\end{array}$ & $5.5 \mathrm{~kW}$ & $55 \mathrm{~kW}-\mathrm{h} / \mathrm{km}$ \\
\hline $\begin{array}{l}10 \% \text { grade at } 60 \\
\mathrm{~km} / \mathrm{h}\end{array}$ & $8 \mathrm{~kW}$ & $130 \mathrm{~kW}-\mathrm{h} / \mathrm{km}$ \\
\hline
\end{tabular}

Steady-state driving requires at least $8-10 \mathrm{~kW}$ of continuous motor power. Acceleration is strongly dependent on motor peak power. We modeled the motor with constant torque up to about $30 \mathrm{~km} / \mathrm{h}$, then constant power at higher speeds. For a motor with 15 $\mathrm{kW}$ peak power, a $0-100 \mathrm{~km} / \mathrm{h}$ acceleration time of about $10 \mathrm{~s}$ is achieved. This is sufficient power for a top speed exceeding $120 \mathrm{~km} / \mathrm{h}$. More detailed analysis based on real motor operating characteristics is required before finalizing the motor selection. The efficiency of electric motors drops rapidly at low loads, so overall efficiency may be reduced if the motor is oversized.

A more accurate estimate of energy consumption was determined using the Simplified Federal Urban Driving Schedule (SFUDS) shown in Error! Reference source not found. to simulate typical stop-and-go urban driving at zero grade [9]. Using the parameter values in Table 1, the energy consumption was calculated to be about $28 \mathrm{~W}-\mathrm{h} / \mathrm{km}$. Without regenerative braking, this increased to about $34 \mathrm{~W}-\mathrm{h} / \mathrm{km}$. The maximum power required in the SFUDS schedule was $6.2 \mathrm{~kW}$.

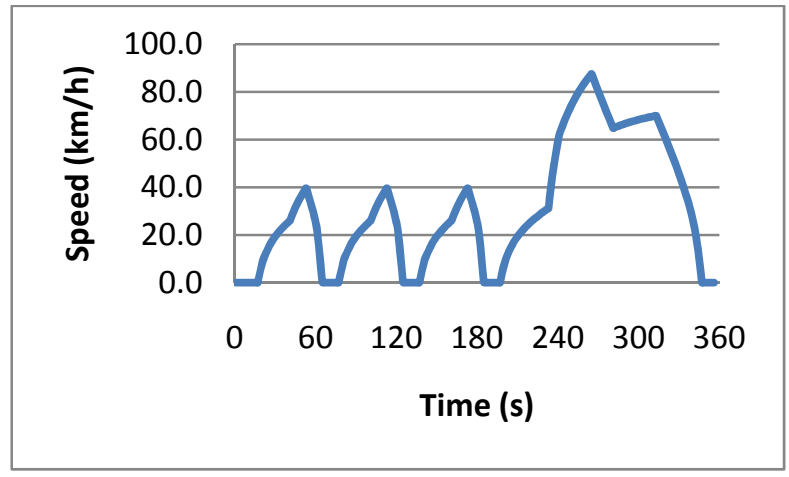

Figure 1. Simplified Federal Urban Driving Schedule (SFUDS) [9]. 
Unlike conventional cars, the energy consumption of the proposed ULV is highest at highway speeds. At a steady speed of $100 \mathrm{~km} / \mathrm{h}$, a $50 \mathrm{~km}$ range will require a battery capacity of about $2.7 \mathrm{~kW}$-h. The best batteries have an energy density of about $250 \mathrm{~W}-\mathrm{h} / \mathrm{kg}$, and the cost is predicted to fall to below $\$ 325 / \mathrm{kW}$-h by 2020 [14]. Using these values, we can calculate the cost and mass of different battery options as shown in Table 3:

Table 3. Battery specifications and range.

\begin{tabular}{|l|l|l|l|l|}
\hline $\begin{array}{l}\text { Battery } \\
\text { capacity }\end{array}$ & $\begin{array}{l}\text { Battery } \\
\text { Mass }\end{array}$ & $\begin{array}{l}\text { Battery } \\
\text { Cost }\end{array}$ & $\begin{array}{l}\text { Urban } \\
\text { Range }\end{array}$ & $\begin{array}{l}\text { Highway } \\
\text { Range }\end{array}$ \\
\hline $2.5 \mathrm{~kW}-\mathrm{h}$ & $10 \mathrm{~kg}$ & $\$ 800$ & $100 \mathrm{~km}$ & $50 \mathrm{~km}$ \\
\hline $5 \mathrm{~kW}-\mathrm{h}$ & $20 \mathrm{~kg}$ & $\$ 1600$ & $200 \mathrm{~km}$ & $100 \mathrm{~km}$ \\
\hline $10 \mathrm{~kW}-\mathrm{h}$ & $40 \mathrm{~kg}$ & $\$ 3200$ & $400 \mathrm{~km}$ & $200 \mathrm{~km}$ \\
\hline
\end{tabular}

A battery capacity of about $5 \mathrm{~kW}$-h will give good range with reasonable cost and mass. Again, these estimates can be refined with more detailed modeling.

\subsection{Can SMPS reduce GHG emissions by 80 - $90 \%$ ?}

The fundamental factors contributing to total GHG emissions from private vehicles are: vehicle energy consumption in $\mathrm{kW}-\mathrm{h} / \mathrm{km}$, vehicle $\mathrm{CO}_{2}$ emissions in $\mathrm{g}$ $\mathrm{CO}_{2} / \mathrm{km}$, average vehicle occupancy in persons/vehicle, and average annual driving distance in $\mathrm{km}$.

Based on the current US car fleet average of $22.1 \mathrm{mpg}$, and load factor of 1.6, the carbon intensity of an average car in the US is about $150 \mathrm{gCO}_{2} /$ person-km [15]. This does not include the total lifecycle emissions of the car, or the well-to-tank emissions which add about $20 \%$ to this total.

The carbon intensity of the US electricity grid in 1999 was about $610 \mathrm{gCO}_{2} / \mathrm{kW}$-h [16]. If we assume a single seat electric vehicle with an energy intensity of $30 \mathrm{~W}$ $\mathrm{h} / \mathrm{p}-\mathrm{km}$, then the carbon intensity for such a vehicle is about $20 \mathrm{gCO}_{2} / \mathrm{p}-\mathrm{km}$. This is a reduction of over $85 \%$ in $\mathrm{CO}_{2}$ emissions compared to a conventional ICE car. If we assume a $50 \%$ reduction in carbon intensity of the US electricity grid, the $\mathrm{CO}_{2}$ reduction increases to 90-95\%. Further reductions are possible if distance travelled per person declines faster than population growth. This assumes that a significant proportion of current trips are discretionary and unnecessary, and that future changes in cities, internet shopping, telecommuting, etc. will further reduce the need to travel.

While there is significant uncertainty in the estimated and predicted values used in this model, it appears that $\mathrm{CO}_{2}$ reductions from private transportation in the order of $85-95 \%$ are achievable by shifting from private ICE cars to SPMS.

\subsection{Will SPMS reduce cost of personal mobility?}

The cost of owning a car typically ranges from $\$ 5000$ $\$ 10,000$ per year. The cost includes vehicle depreciation, financing costs, insurance, licensing, parking, maintenance and fuel. Most of these costs are fixed, so there is little incentive to reduce travel. In fact, there is an incentive to travel frequently and unnecessarily because of the convenience, and to justify the fixed costs. In other words, the more you drive, the lower the cost per $\mathrm{km}$.

In contrast, SPMS provides personal mobility as a payas-you-go service. With this model, the more you travel the more you pay. It is likely that annual travel distances will reduce substantially as users curtail unnecessary trips to save money. For example, if a car owner spends $\$ 7000$ per year to own a car, and drives $14,000 \mathrm{~km}$ per year, the cost per $\mathrm{km}$ is $\$ 0.50$. If the fixed cost is $\$ 6000$, and the owner drives only 7000 $\mathrm{km}$, the total cost is still $\$ 6500$, and the cost per $\mathrm{km}$ increases to nearly $\$ 1.00$.

Alternatively, if the SPMS flat rate is $\$ 0.50 / \mathrm{km}$, travelling $7000 \mathrm{~km}$ would cost \$3500, saving about $\$ 3000$ per year. A high mileage driver, on the other hand, would spend more than the comparable car ownership cost. If the break-even point occurs at high mileage, say $30,000 \mathrm{~km} /$ year, then the majority of drivers would save money using SPMS instead of a private car.

In order to be sustainable without government subsidies, the cost of operating the SPMS must be less than the revenues from user fees. The operating costs include vehicle depreciation, maintenance, energy, parking, and charging infrastructure. The vehicle costs will be shared among more users than is the case with private cars, so the costs should be sufficiently low. The additional infrastructure costs are uncertain, but infrastructure can be developed incrementally, and does not involve expensive or immature technologies. 


\section{$5 \quad$ Social and cultural issues}

The SPMS concept appears to be feasible from technical and economic viewpoints. However, the private car is deeply embedded in the culture of the developed world, and is a powerful symbol of status and success. We hope that the private car eventually recedes to becoming a niche product for displays of conspicuous consumption, and that the majority of people come to prefer the convenience and cost savings of SPMS. Perhaps cars can be replaced by more sustainable status symbols, like original art and expensive wristwatches.

\section{Future work}

The SPMS is an example of a new and sustainable solution to a real problem. The SPMS concept is a platform for many related design problems, including information systems, network management, infrastructure design, intelligent grids, renewable energy, etc. An immediate project is the design of an ULV to be used by SPMS. This has become the new focus for the Western Sunstang solar car team, and could be an ideal challenge for design teams at other universities as well.

\section{References}

[1] Canadian Engineering Accreditation Board (2008), Accreditation Criteria and Procedures 2008, Engineers Canada.

[2] Gore, A. (2009). Our choice :A plan to solve the climate crisis. New York: Melcher Media.

[3] Brown, L. (2009). Plan B 4.0: Mobilizing to save civilization. New York; London: W. W. Norton.

[4] Monbiot, G. (2006). Heat: How to stop the planet burning. London; New York: Allen Lane.

[5] Buchal, R. O. (2010), Designing the Car of the Future, Canadian Engineering Education Association (CEEA) Inaugural Conference, Kingston Ontario, June 7-9, 2010.

[6]Mitchell, M.J., Borroni-Bird, C.E., Burns, L.D. (2010). Reinventing the automobile: Personal urban mobility for the 21st century. MIT Press.

[7] Jacobson, M.Z. (2009), Review of Solutions to global warming, air pollution and energy security, Energy \& Environmental Science, 2009, 2, pp 148-173.
[8] TREV (Two-Seater Renewable Energy Vehicle), University of South Australia,

http://www.unisa.edu.au/solarcar/Trev/ , Accessed May 6, 2011.

[9] Larminie, J., Lowry, J. (2003). Electric Vehicle Technology Explained. West Sussex, England: Wiley.

[10] Low Rolling Resistance Tires, Wikipedia, http://en.wikipedia.org/wiki/Low-rolling resistance tires , accessed May 6, 2011.

[11] Carroll, D.R. (2003). The Winning Solar Car, SAE International, Warrenville Pa.

[12] Loremo, http://www.loremo.com/ , accessed May 6, 1011.

[13] Lithium-ion Batteries, Wikipedia, http://en.wikipedia.org/wiki/Lithium-ion_battery, accessed May 6, 2011.

[14] Lache, R., Galves, D., Nolan, P. (2010). Vehicle Electrification Industry Update, Deutsche Bank, http://gmvolt.com/files/DB_EV_Growth.pdf, accessed May 2, 2011.

[15] US Department of Energy (2010). Transportation Energy Data Book: Edition 29. (ORNL-6985)

[16] US Department of Energy (2000).Carbon Dioxide Emissions from the Generation of Electric Power in the United States. 